\title{
Role of chlorine dioxide in NDMA formation from oxidation of model amines
}

\section{Wenhui Gan ${ }^{1}$, Tom Bond ${ }^{2}$, Xin Yang ${ }^{1 *}$, Paul Westerhoff ${ }^{3}$}

${ }^{1}$ SYSU-HKUST Research Center for Innovative Environmental Technology, School of Environmental Science and Engineering, Sun Yat-sen University, Guangzhou 510275, China

${ }^{2}$ Department of Civil and Environmental Engineering, Imperial College London, London SW7 2AZ, United Kingdom

${ }^{3}$ Arizona State University, School of Sustainable Engineering and the Built Environment, Tempe, AZ 85287-3005, USA

*Corresponding author, Tel: +86-2039332690, email: yangx36@mail.sysu.edu.cn 
1 Abstract.

2 N-nitrosodimethylamine (NDMA) is an emerging disinfection by-product, and we show 3 that use of chlorine dioxide $\left(\mathrm{ClO}_{2}\right)$ has the potential to increase NDMA formation in waters 4 containing precursors with hydrazine moieties. NDMA formation was measured after 5 oxidation of 13 amines by monochloramine, $\mathrm{ClO}_{2}$ and pre-treatment with $\mathrm{ClO}_{2}$ followed by 6 post-monochloramination. Daminozide, a plant growth regulator, was found to yield

$7 \quad 5.01 \pm 0.96 \%$ NDMA upon reaction with $\mathrm{ClO}_{2}$, although no NDMA was recorded during 8 chloramination. The reaction rate was estimated to be $\sim 0.0085 \mathrm{~s}^{-1}$ and based upon our 9 identification by mass spectrometry spectra of intermediates the reaction likely proceeds via 10 the hydrolytic release of unsymmetrical dimethylhydrazine (UDMH), with the hydrazine 11 structure a key intermediate in NDMA formation. The presence of UDMH was confirmed by 12 gas chromatography-mass spectrometry (GC-MS) analysis. For 10 of the 13 compounds, $13 \mathrm{ClO}_{2}$ pre-oxidation reduced NDMA yields compared with monochloramination alone, which 14 is explained by our measured release of DMA. This work shows potential pre-oxidation 15 strategies to control NDMA formation may not impact all organic precursors uniformly, so 16 differences might be source specific depending upon occurrence of different precursors in 17 source waters. For example, daminozide is a plant regulator so drinking water that intakes heavily influenced by upstream agricultural runoff could be at risk. 
24 TOC/Abstract Art.

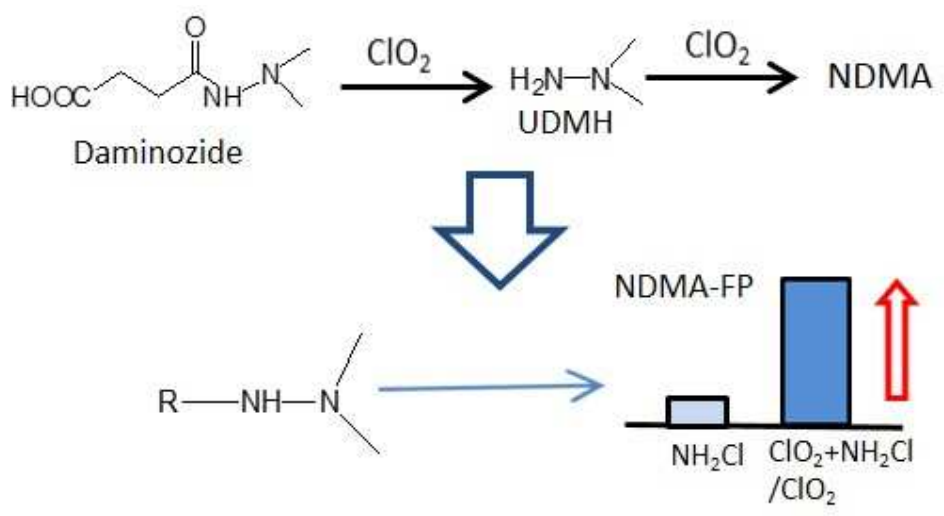

25

26

27

28

29

30

31

32

33

34

35

36

37

38 


\section{Introduction.}

N-nitrosodimethylamine (NDMA) is acutely carcinogenic, with a concentration of only $0.7 \mathrm{ng} \cdot \mathrm{L}^{-1}$ associated with a $10^{-6}$ lifetime cancer risk level ${ }^{1}$. California has issued a notification level of $10 \mathrm{ng} \cdot \mathrm{L}^{-1}$ for NDMA in drinking waters and the United States Environmental Protection Agency (USEPA) included it in Contaminant Candidate List 3, for pollutants which may be considered for future regulation ${ }^{2,3}$. Concern about NDMA has been heightened by the increasing prevalence of polluted sources being used to produce drinking water. For example, waters affected by wastewater effluents frequently produce higher NDMA concentrations ${ }^{4}$.

In order to minimize risks associated with NDMA, it is imperative we improve our knowledge of NDMA precursors and the pathways by which they generate NDMA. Previous work suggested that DMA and monochloramine reacted to form unsymmetrical dimethylhydrazine (UDMH), which could then be oxidized to NDMA ${ }^{5}$. Subsequently, chlorinated unsymmetrical dimethylhydrazine (Cl-UDMH) was suggested as an important intermediate after nucleophilic attack of DMA on dichloramine ${ }^{6}$. However, whereas molar yields of NDMA from chloramination of DMA are low $\left(\sim 1-2 \%^{7,8}\right)$, it has been demonstrated that some tertiary amines are far more potent precursors (i.e., higher molar yields upon chloramination). NDMA yields from chloramination of specific tertiary amines like methadone and ranitidine were over $50 \%{ }^{9,10}$. Various mechanisms, including nucleophilic substitution $^{11}$ and chlorine transfer followed by DMA release ${ }^{8}$ have been proposed to explain NDMA formation from tertiary amines such as ranitidine. It has also been highlighted that both monochloramine and dichloramine may play important roles in NDMA formation, for example, from ranitidine and N,N-dimethyl-isopropylamine, respectively ${ }^{9}$. 
62 Besides chloramines, oxidation of water samples by chlorine dioxide $\left(\mathrm{ClO}_{2}\right)$ can also 63 form NDMA ${ }^{12,13}$. A small number of amines have been identified which can generate low 64 yields of NDMA during oxidation by $\mathrm{ClO}_{2}$, for example, ranitidine and dimethylaniline 65 (NDMA yields 0.055 and $0.016 \% \mathrm{~mol} / \mathrm{mol}$, respectively) $)^{14}$. DMA does not have a high 66 NDMA yield from reaction with $\mathrm{ClO}_{2}{ }^{15} \cdot \mathrm{ClO}_{2}$ is a selective oxidant due to its ability to 67 abstract one electron ${ }^{16}$. This means mechanisms which generate NDMA are likely to be 68 different from application of chloramination. $\mathrm{ClO}_{2}$ is applied for control of color, taste and 69 odor $^{17}$. And it is used as either a primary or secondary disinfectant, in the former case typically followed by secondary disinfectant, like chlorine and chloramine, to provide a distribution system residual ${ }^{18}$. As a secondary disinfectant, formation of NDMA has been observed in surface water after $\mathrm{ClO}_{2}$ treatment ${ }^{12}$. As a primary disinfectant, $\mathrm{ClO}_{2}$ pretreatment followed by chloramination has exhibited inconsistent results for NDMA formation. Lee et al. reported that $\mathrm{ClO}_{2}$ pretreatment of surface waters dramatically decreased NDMA formation ${ }^{15}$, whereas Shah et al. found that $\mathrm{ClO}_{2}$ did not effectively reduce NDMA formation, and even increased NDMA in certain waters impacted by wastewater ${ }^{13}$. This indicates that pre-oxidation with $\mathrm{ClO}_{2}$ can either deactivate specific precursors or convert them into more potent forms, depending on their identity. Further, Selbes and co-workers reported that NDMA yields of model tertiary amines after pre-oxidation with $\mathrm{ClO}_{2}$ became similar to that from DMA i.e. that yields decreased for precursors more reactive than DMA and increased for the less potent precursors ${ }^{19}$. This suggests NDMA formation proceeded through the intermediate release of DMA. Nevertheless, the underlying oxidation mechanism responsible for the conflicting observations regarding influence of $\mathrm{ClO}_{2}$ pretreatment on NDMA formation remains unclear. 
87 NDMA formation through testing the NDMA formation potential (NDMA-FP) from amine precursors, with and without post-oxidation by chloramines. Model compounds were chosen to cover a variety amount of structures, including pharmaceuticals, personal care products (PPCPs), agricultural products and industrial contaminants with DMA functional groups. Model compounds with hydrazine moieties were also chosen as they had similar structures as NDMA. The occurrence of these compounds in surface water has been shown to be in the range of several $\mathrm{ng} / \mathrm{L}$ to tens of $\mu \mathrm{g} / \mathrm{L}^{20,21}$. For comparison, NDMA-FP with chloramination was also determined. The impact of $\mathrm{ClO}_{2}$ dose, contact time and $\mathrm{pH}$ were also examined for selected precursors. Finally, the influence of a reactive precursor on NDMA-FP in authentic wastewater samples was estimated.

\section{Materials and methods.}

Regents. Thirteen model compounds which possess a variety of chemical functionality were investigated (Figure 1), ranitidine was purchased from Alfa Aesar (USA), with the others obtained from J\&K (China). Stock solutions $(1 \mathrm{mM})$ of each model compound were prepared in either ultrapure water or acetonitrile. UDMH was obtained from Sigma (USA). Mixed nitrosamine calibration standards were purchased from Supelco (USA) and d6-NDMA was bought from Cambridge Isotope Laboratories (USA). Acetonitrile of HPLC grade was purchased from Merck (Germany). Dichloromethane was obtained from J\&K (China). Resprep EPA Method 521 solid phase extraction (SPE) cartridges (6 mL/2 g) from Restek (USA) were used to pre-concentrate NDMA before analysis.

Monochloramine stock solutions were prepared daily by mixing equal volumes of diluted sodium hypochlorite $(\mathrm{NaOCl})$ (Sigma, USA) and ammonium chloride solution at a molar ratio of $0.8: 1$ at $\mathrm{pH}$. As with previous studies into oxidation by $\mathrm{ClO}_{2}, \mathrm{ClO}_{2}$ solution 
111 was prepared daily from gaseous $\mathrm{ClO}_{2}$ by slowly adding dilute $\mathrm{H}_{2} \mathrm{SO}_{4}$ to a sodium chlorite

$112\left(\mathrm{NaClO}_{2}\right)$ solution using a set of glass gas diffusion bottle reactors, according to the standard

113 method $^{22}$. Consecutively, the resulting gas was collected and pumped through saturated

$114 \mathrm{NaOCl}_{2}$ solution and then collected into ice cold ultrapure water to produce a $\mathrm{ClO}_{2}$ solution.

115 Concentrations of $\mathrm{ClO}_{2}$ and monochloramine were determined by the N-N-diethyl-p-

116 phenylene diamine (DPD) - ferrous ammonium sulfate (FAS) titration method $^{18,22}$.

117 Experimental procedures. All experiments were undertaken in duplicate and pH levels

118 were controlled using phosphate buffer. When $\mathrm{ClO}_{2}$ was used as sole oxidant, NDMA

119 formation potentials (NDMA-FPs) were tested with $\mathrm{ClO}_{2}$ in excess and a 5-day reaction time,

120 following previous studies ${ }^{8}$. Each model compound was diluted to $2 \mu \mathrm{M}$, except for

121 benzalkonium chloride and polyDADMAC, which were diluted to $2 \mathrm{mg} \cdot \mathrm{L}^{-1}$, at $\mathrm{pH} 7$ in $1 \mathrm{~L}$

122 amber bottles. $\mathrm{ClO}_{2}$ was added at $0.2 \mathrm{mM}$ before being left in the dark for 5 days at room

123 temperature $\left(22 \pm 1^{\circ} \mathrm{C}\right)$, before residual $\mathrm{ClO}_{2}$ was quenched by sodium thiosulfate. A series of

124 experiments with monochloramine as the oxidant were also conducted using the same

125 concentrations and contact times as the $\mathrm{ClO}_{2}$ tests. When $\mathrm{ClO}_{2}$ was used for pre-oxidation, 20

$126 \mu \mathrm{M} \mathrm{ClO}_{2}$ was applied to $2 \mu \mathrm{M}$ model compound at $\mathrm{pH}$ 7. After 15 min, residual $\mathrm{ClO}_{2}$ was

127 measured (Table S1) and quenched by adding a stoichiometric amount of sodium thiosulfate

128 solution, based following equation:

$129 \mathrm{~S}_{2} \mathrm{O}_{3}^{2-}+4 \mathrm{ClO}_{2}+3 \mathrm{H}_{2} \mathrm{O} \rightarrow 2 \mathrm{SO}_{4}^{2-}+3 \mathrm{ClO}_{2}^{-}+\mathrm{Cl}^{-}+6 \mathrm{H}^{+}$.

130 The removal of $\mathrm{ClO}_{2}$ was confirmed using the DPD-FAS method. Afterwards, 131 monochloramine solution $(0.2 \mathrm{mM})$ was added for NDMA-FP tests as described above. 132 Residual chloramine concentrations in every sample were confirmed after 5-day reaction.

Further testing for NDMA formation and dimethylamine (DMA) release was conducted 134 with $\mathrm{ClO}_{2}$ and/or monochloramine for the more reactive organic precursors. Tests used higher 
135 precursor concentrations of $0.1 \mathrm{mM}$ with NDMA being directly analyzed without solid phase 136 extraction (SPE). When $\mathrm{ClO}_{2}$ was used as the sole oxidant doses varied from 0.2 to $2 \mathrm{mM}$ and 137 reaction times from 10 seconds to 5 days. When $\mathrm{ClO}_{2}$ was used as a pre-oxidant, the applied 138 doses were the same, with a reaction time of $15 \mathrm{~min}$. After residual chlorine dioxide was 139 quenched, samples were reacted with $2 \mathrm{mM}$ monochloramine for 5 days as described above.

140 The influent and effluent samples from a municipal wastewater treatment plant in South 141 China were collected and the detailed treatment processes are described in Text S2 in the 142 supporting information. The concentrations of daminozide were analyzed. The formation 143 potential of NDMA from influent wastewater was also investigated by reacting with $2 \mathrm{mM}$ 144 chlorine dioxide for 5 days at $\mathrm{pH} 7$.

Analytical methods. NDMA was concentrated by a factor of 500 by SPE prior to analysis using Ultra Performance Liquid Chromatography tandem mass spectrometry 147 (UPLC/MS/MS) based on the method of Ripollés and co-workers ${ }^{23}$. In brief, NDMA samples $148(500 \mathrm{~mL})$ were spiked with $500 \mathrm{ng} \cdot \mathrm{L}^{-1} \mathrm{~d} 6-\mathrm{NDMA}$ as internal standard and concentrated by 149 SPE extraction. $15 \mathrm{~mL}$ dichloromethane was used to elute NDMA before samples were 150 further concentrated to $1 \mathrm{~mL}$ using a rotary evaporator at $30^{\circ} \mathrm{C}^{24}$. For NDMA analysis 151 without SPE extraction, samples were directly sent to UPLC/MS/MS. The detection limit of 152 the method (SPE-UPLC/MS/MS) was $0.67 \mathrm{nM}$. Relative recoveries of NDMA, once 153 corrected using the internal standard, ranged from 94 to $102 \%$. DMA was quantified by gas 154 chromatography-mass spectrometry (GC-MS) after derivation with benzenesulphonyl 155 chloride (BSC) solution based on the method of Wang et $\mathrm{al}^{21}$. The detection limit for DMA 156 was $2.2 \mathrm{nM}$. Additional details of the NDMA and DMA analysis are supplied as Text S1 in 157 the Supporting Information (SI). Daminozide in wastewater samples was analyzed by 158 UPLC/MS/MS after being concentrated on SPE (please see the SI). 
Analysis of UDMH was based on the method of Rutschmann et al ${ }^{25}$, with pentafluorobenzoyl chloride (PFB-Cl) as the derivatization agent and using GC-MS for quantification. Quantification of UDMH was carried out by selected ion monitoring (SIM) using the molecular ion (M+) at m/z 448 and fragment ions at $\mathrm{m} / \mathrm{z} 181,195$, and 253. Details of UDMH analysis are supplied in the SI.

\section{Results and discussion}

NDMA formation during oxidation with chlorine dioxide. Six of the 13 precursors formed detectable levels $(\geqslant 0.034 \% \mathrm{~mol} / \mathrm{mol})$ of NDMA during oxidation with chlorine dioxide (Table 1 and Figure S1). DMA formed no detectable NDMA during $\mathrm{ClO}_{2}$ oxidation (Table 1). NDMA yields from TMA, DMBzA and DMPD were around $0.1 \%$ in each case, while tetracycline and DMDC produced $0.31 \pm 0.01 \%$ and $0.48 \pm 0.01 \%$, respectively (Table 1 ). Padhye and coworkers reported NDMA formation from direct reaction between $\mathrm{ClO}_{2}$ and DMDC, albeit at a lower yield $(0.004 \%)^{26}$, than the one in the current study. This difference may be explained by the longer reaction time of 5 days (rather than $24 \mathrm{~h}$ ) and higher $\mathrm{ClO}_{2}$ dose of $0.2 \mathrm{mM}$ (rather than $0.1 \mathrm{mM}$ ) used in the current study. Also, tetracycline was observed as a NDMA precursor during $\mathrm{ClO}_{2}$ oxidation ${ }^{14}$. Since reaction between DMA and $\mathrm{ClO}_{2}$ did not generate detectable levels of NDMA, this indicates that DMA was not an important intermediate in NDMA formation during oxidation of the other precursors by $\mathrm{ClO}_{2}$. Daminozide was the most potent precursor, having a molar NDMA yield of $5.01 \pm 0.96 \%$. To our knowledge this is the first time such high NDMA yields have been reported from reactions between amines and $\mathrm{ClO}_{2}$.

Daminozide contains a hydrazine $\left(\left(\mathrm{R}_{1} \mathrm{R}_{2}\right) \mathrm{N}-\mathrm{N}\left(\mathrm{R}_{3} \mathrm{R}_{4}\right)\right)$ functionality (Figure 1$)$, which means that there is no requirement for an external nitrogen source during NDMA formation, 
183 as is the case for the other precursors. Daminozide is analogous to 1, 1-dimethylhydrazine

184 (UDMH) in this respect. It is interesting to note that high yields of NDMA from ozonation of both these compounds have been reported: $55 \%$ and $80 \%$ from daminozide and UDMH respectively ${ }^{27}$. It is also relevant that there are multiple analytical methods for quantification of daminozide which rely upon hydrolysis of daminozide to UDMH followed by derivatization of the latter ${ }^{28}$.

Since the mechanism which leads to NDMA formation from reaction between daminozide and $\mathrm{ClO}_{2}$ is unresolved, the relevant pathways were investigated further. Aqueous reactions involving $\mathrm{ClO}_{2}$ may proceed through one-electron abstraction with chlorite release ${ }^{29}$, instead of oxidative substitution or addition, as can occur with chlorine or chloramines ${ }^{30}$. For daminozide, the most likely sites for initial reaction with $\mathrm{ClO}_{2}$ are the two nitrogen lone pairs. Thus, a mechanism is proposed as one possible pathway in which initial electron abstraction precedes release of either DMA or UDMH by hydrolysis (Figure 2). Further, since no NDMA was detected during reaction between DMA and $\mathrm{ClO}_{2}$ (Table 1), it was likely that UDMH, rather than DMA, was the key intermediate in NDMA formation. Moreover, UDMH formation was confirmed by using GC-MS during reaction between daminozide and $\mathrm{ClO}_{2}$

200 (Figure S2 and S3). UDMH yields as functions of oxidant dose during 5 min exposure of daminozide to $\mathrm{ClO}_{2}$ (Figure S4) and at constant $\mathrm{ClO}_{2}$ dose of 5:1 at variable contact times of up to $60 \mathrm{~min}$ (Figure S5) were also investigated. The detected UDMH release from daminozide ranged from 0.2 to $0.6 \%$ at $\mathrm{ClO}_{2}$ to daminozide molar ratios from 1:0.1 to $1: 1$ and 5 min contact time. At higher $\mathrm{ClO}_{2}$ doses, levels of UDMH decreased and it was barely detected when the dose increased to $10: 1$, possibly due to rapid reaction with $\mathrm{ClO}_{2}$ (Figure S4). Furthermore, UDMH release from daminozide was observed to increase during the first 
208 thereafter decrease rapidly (Figure S5). These data are in agreement with the hypothesis that 209 UDMH release from daminozide is likely to be the rate-limiting step in NDMA formation.

The behavior of daminozide and UDMH under relevant oxidation scenarios was directly compared in order to investigate whether NDMA formation can be explained by release of 212 the latter from the former. NDMA yields from oxidation of daminozide steadily increased 213 from $1.22 \pm 0.06 \%$ at a $\mathrm{ClO}_{2}$ dose of $2: 1$ to $3.61 \pm 0.10 \%$ at a $\mathrm{ClO}_{2}$ dose of 20:1 after 5-day reaction (Figure 3a). Equivalent experiments with UDMH as a precursor exhibited a similar pattern: from NDMA formation of $1.10 \pm 0.03 \%$ at a $\mathrm{ClO}_{2}$ dose of $2: 1$ to $3.42 \pm 0.04 \%$ at a dose of 20:1 (Figure 3a). Furthermore, a linear relation with $\mathrm{R}^{2}=1.00$ was observed between NDMA formation from UDMH and daminozide, when these two precursors were oxidized by $\mathrm{ClO}_{2}$ under the same reaction conditions (Figure 4). This supports the hypothesis that NDMA formation from daminozide proceeds via oxidation of UDMH. It should also be noted that NDMA yields from UDMH were consistently about $95 \%$ of those from daminozide at $\mathrm{ClO}_{2}$ pre-oxidation doses of 2:1 to 20:1 (Figure 3a), which indicated other minor formation pathways also contribute. Another notable feature of NDMA formation from oxidation of daminozide with $\mathrm{ClO}_{2}$ was its rapid formation kinetics, with a $0.0085 \mathrm{~s}^{-1}$ estimated pseudofirst order reaction rate constant (k) (Table S2 and Figure S6). The estimate of k was based on the following kinetic model developed by Shen and co-workers ${ }^{31}$ by fitting NDMA conversion curve of daminozide with $\mathrm{ClO}_{2}$ oxidation: $Y=\frac{\theta}{1+10^{k \cdot(\operatorname{Lag}-\mathrm{t})}}$, where $\mathrm{Y}$ is the NDMA molar conversion at given reaction time $(\mathrm{t}) ; \theta$ is the maximum molar conversion obtained at kinetic testing; Lag is the time required to achieve $50 \%$ of the ultimate molar conversion.

To complement these results, DMA "release" following oxidation of daminozide was quantified (Figure 5). While no DMA was detected from chloramination of daminozide, low yields were observed during oxidation by $\mathrm{ClO}_{2}$ from $1.86 \pm 0.05 \%$ at a $\mathrm{ClO}_{2}$ dose of $2: 1$ to 
$2320.03 \pm 0.01 \%$ at a dose of $20: 1$. The decreased DMA release with increasing $\mathrm{ClO}_{2}$ dose could 233 be due to the transformation to the pathway of UDMH release. These DMA yields cannot 234 account for the observed NDMA formation during $\mathrm{ClO}_{2}$ oxidation of daminozide.

Figure 3c displays the effect of $\mathrm{pH}$ on NDMA formation from daminozide from reaction with $\mathrm{ClO}_{2}$. The highest formation occurred at $\mathrm{pH} 6$ and 7. After a 3-day reaction time, 237 NDMA yields were $3.24 \pm 0.14 \%$ and $3.50 \pm 0.11 \%$ respectively at $\mathrm{pH} 6$ and 7 , while only $0.80 \pm 0.06 \%$ and $2.07 \pm 0.04 \%$ was recorded at $\mathrm{pH} 5$ and 8 , respectively.

It was previously noted that $\mathrm{ClO}_{2}$ reacted faster with deprotonated amines than protonated ones, therefore $\mathrm{pH}$ may affect NDMA-FPs resulting from reaction with $\mathrm{ClO}_{2}{ }^{15,19}$. Further, Lee et $\mathrm{al}^{15}$ noted apparent rate constants for oxidation of amines by $\mathrm{ClO}_{2}$ vary with $\mathrm{pH}$, since deprotonated amines react more strongly with $\mathrm{ClO}_{2}$. Therefore, rate constants of tested amines reached a stable maximum at $\mathrm{pH}$ values above the amine's $\mathrm{p} K_{\mathrm{a}}$. Although the DMA moiety of daminozide has a $\mathrm{p} K_{\mathrm{a}}$ of $2.8^{32}$, NDMA formation from reaction between $\mathrm{ClO}_{2}$ and daminozide reached a peak at $\mathrm{pH}$ 6-7 (Figure 3c). Therefore, this indicates that the initial reaction between daminozide and $\mathrm{ClO}_{2}$ was not the rate-determining step in NDMA

247 formation. Instead, as UDMH has a $\mathrm{p} K_{\mathrm{a}}$ value of $7.21^{33}$, it's reasonable that oxidation of $\mathrm{UDMH}$ by $\mathrm{ClO}_{2}$ reached higher efficiency at circumneutral $\mathrm{pH}$ and that this step is relevant to the overall NDMA yield. Equivalent experiments to assess the impact of $\mathrm{pH}$ were undertaken with UDMH and these displayed a similar pattern with daminozide, with NDMA yields of $1.72 \pm 0.14 \%, 3.04 \pm 0.10 \%, 3.32 \pm 0.05 \%$ and $1.94 \pm 0.04 \% \%$ at $\mathrm{pH} 5,6,7$ and 8 respectively (Figure 3c). This indirectly indicated that UDMH was the important intermediate from daminozide to react with $\mathrm{ClO}_{2}$ to form NDMA. DMA formation from oxidation of daminozide by $\mathrm{ClO}_{2}$ was low at all $\mathrm{pH}$ levels (Figure 3d). In contrast to NDMA formation from this precursor, DMA increased with $\mathrm{pH}$, to a maximum of $0.15 \pm 0.05 \%$ at $\mathrm{pH} 8$ (Figure 3d), which indicates base catalyzed hydrolysis of daminozide releases DMA. 
NDMA formation during oxidation by monochloramine. The NDMA yields during chloramination from this study are comparable with those reported previously (Table 1). In particular, those from DMBzA, DMDC, DMAI, BAC, ranitidine and polyDADMAC agree well with previous literature ${ }^{15,34-36}$ (Table 1). Conversely, daminozide did not form a detectable amount of NDMA during chloramination, a contrast to its behavior during reaction with $\mathrm{ClO}_{2}$.

To compare with data from daminozide, NDMA formation from oxidation of UDMH by $\mathrm{NH}_{2} \mathrm{Cl}$ was also investigated. Yields were low and varied from $0.30 \pm 0.02 \%$ to $0.50 \pm 0.03 \%$ at molar $\mathrm{NH}_{2} \mathrm{Cl}$ doses of 2:1 - 20:1 (Figure 3b). These data provide further evidence that $\mathrm{ClO}_{2}$, rather than $\mathrm{NH}_{2} \mathrm{Cl}$, was the oxidant largely responsible for NDMA formation from both daminozide and UDMH.

NDMA formation during oxidation by chlorine dioxide-monochloramine. NDMA formation from ten out of 13 precursors was reduced upon $\mathrm{ClO}_{2}$ pre-oxidation, relative to yields from chloramination alone. For example, reductions in NDMA formation of 94\%, $73 \%, 68 \%$ and $67 \%$ for DMAP, DMDC, DMBzA and ranitidine, respectively (Table 1). Moreover, NDMA formation from the quaternary amine polymer BAC was reduced by $21 \%$ and that from DMAI was reduced by $29 \%$. Pretreatment using $\mathrm{ClO}_{2}$ caused a small increase in the NDMA yield from DMPD, from $0.3 \pm 0.02 \%$ to $0.5 \pm 0.02 \%$. Only for daminozide did $\mathrm{ClO}_{2}$ pre-oxidation enhance NDMA formation, as $5.04 \pm 0.21 \%$ was measured during oxidation by $\mathrm{ClO}_{2}-\mathrm{NH}_{2} \mathrm{Cl}$, while no NDMA was formed from monochloramination alone. $\mathrm{ClO}_{2}$ pretreatment was also observed to effectively reduce NDMA formation from ranitidine, DMBzA and DMDC in previous studies ${ }^{15,19}$. In addition, enhanced NDMA conversion from reaction between daminozide and $\mathrm{ClO}_{2}$ was reported by Selbes and co-workers, relative to that during chloramination. However, the increased NDMA conversion was attributed to 
281 DMA release from daminozide ${ }^{19}$, rather than the pathway via UDMH proposed in this study.

282 Moreover, NDMA formation from oxidation of daminozide by $\mathrm{ClO}_{2}$ alone (without postoxidation by chloramines) was not evaluated in the earlier study.

It has been proposed in literature that NDMA precursors can be decomposed to either

DMA or oxidation products containing a DMA functional group during pre-oxidation with $286 \mathrm{ClO}_{2}$, which resulted in NDMA-FPs similar to that of DMA after post-chloramination ${ }^{19}$. This explanation is consistent with the effect of $\mathrm{ClO}_{2}$ pre-oxidation on DMDC and DMAP, which reduced NDMA-FP yields by $75 \%$ and $>95 \%$, respectively (Table 1). The NDMA-FP reduction of polyDADMAC was more likely due to the degradation to monomers by $\mathrm{ClO}_{2}$, rather than conversion to DMA or TMA, because NDMA yield after pre-oxidation with $\mathrm{ClO}_{2}$ was far less than that from DMA or TMA, namely $0.04 \pm 0.01 \%$. Previous studies found that polyDADMAC monomers are less reactive than the quaternary polymer and consequently didn't significantly reduce NDMA-FP from polyDADMAC ${ }^{38}$. Differences in experimental conditions account for these differences. In our study, NDMA-FP was measured after 5-days, whereas NDMA-FP was tested only after 1-day in the earlier study ${ }^{38}$.

Ranitidine, DMAI and daminozide were selected for further experiments to study the effect of $\mathrm{ClO}_{2}$ pretreatment considering their relatively high NDMA-FPs during $\mathrm{ClO}_{2}-\mathrm{NH}_{2} \mathrm{Cl}$ and the contrasting effect of $\mathrm{ClO}_{2}$ pretreatment on these precursors.

Increasing $\mathrm{ClO}_{2}$ dose during pre-oxidation of daminozide by $\mathrm{ClO}_{2}-\mathrm{NH}_{2} \mathrm{Cl}$ enhanced NDMA formation: from $1.02 \pm 0.04 \%$ to $3.50 \pm 0.01 \%$, as the $\mathrm{ClO}_{2}$ dose increased from 0.2 $\mathrm{mM}$ to $2 \mathrm{mM}$ of $\mathrm{ClO}_{2}$ (Figure 5). Liberation of DMA from daminozide followed the opposite pattern, as it decreased from $1.86 \pm 0.04 \%$ at a $\mathrm{ClO}_{2}$ dose of $0.2 \mathrm{mM}$ to $0.03 \%$ at a $\mathrm{ClO}_{2}$ dose of $2 \mathrm{mM}$ (Figure 5). Therefore, release of DMA cannot account for the considerable 
enhancement of NDMA yields with increased $\mathrm{ClO}_{2}$ pre-oxidation doses. The behavior of UDMH when oxidized by $\mathrm{ClO}_{2}-\mathrm{NH}_{2} \mathrm{Cl}$ was directly compared with that of daminozide. UDMH was observed to follow a similar trend to daminozide, as NDMA yields increased with larger $\mathrm{ClO}_{2}$ pre-oxidant doses and yields from the two precursors were always within $0.3 \%$ of each other under the various $\mathrm{ClO}_{2}$ pre-oxidation doses.

Results from experiments with ranitidine at various $\mathrm{ClO}_{2}$ pre-oxidation doses showed that higher $\mathrm{ClO}_{2}$ doses enhanced the reduction of NDMA-FP, relative to the amount produced by chloramination alone (Figure S7). The reductions in NDMA-FP at $\mathrm{ClO}_{2}$ doses of $0.2,0.5$, 1 and $2 \mathrm{mM}$ were $54 \%, 93 \%, 95 \%$ and $98 \%$, respectively. This illustrates higher $\mathrm{ClO}_{2}$ preoxidation doses enhanced the reduction of NDMA. We quantified DMA release during the experiments. Release of DMA from ranitidine after pre-oxidation increased with increasing $\mathrm{ClO}_{2}$ doses, from $0.83 \pm 0.15 \%$ at $0.2 \mathrm{mM} \mathrm{ClO}_{2}$ to $1.96 \pm 0.09 \%$ at $2 \mathrm{mM} \mathrm{ClO}_{2}$ (Figure S7). Therefore, the lower NDMA yield from ranitidine following $\mathrm{ClO}_{2}$ pre-oxidation can be explained by with cleavage of DMA and/or TMA from the furan moiety.

Equivalent experiments with DMAI (Figure S7) showed $\mathrm{ClO}_{2}$ pretreatment reduced NDMA formation, by $45 \%$ at a $\mathrm{ClO}_{2}$ dose of 2:1. However, increasing the $\mathrm{ClO}_{2}$ dose resulted in no additional reduction in NDMA-FP yield. Meanwhile, stable DMA yields (about 8\%) from DMAI was observed as the $\mathrm{ClO}_{2}$ doses from 5:1 to 20:1 (Figure S7). This implies that liberation of DMA was facile from this precursor and did not increase at the higher $\mathrm{ClO}_{2}$ preoxidation doses used. As with ranitidine the observed decrease in NDMA formation can be explained by liberation of a less reactive precursor fragment, i.e. DMA and/or TMA.

Implications for water treatment. $\mathrm{ClO}_{2}$ as a primary disinfectant is effective to inactivate majority of tertiary amines ${ }^{15}$. However, as highlighted by the high yields of NDMA reported in the current study from daminozide, deployment of $\mathrm{ClO}_{2}$ as a primary or pre- 
329 oxidant during water treatment has the potential to enhance NDMA formation in waters 330 containing precursors with hydrazine moieties. Its application was restricted to non-food 331 crops in 1989 in the $\mathrm{USA}^{39}$ due to concern about the possible carcinogenic effects arising 332 from exposure to it and its degradation product $\mathrm{UDMH}^{40}$. Nonetheless, daminozide is still 333 manufactured $^{41}$ and applied as a plant growth regulator ${ }^{25}$, with regulatory approval in the EU, 334 Australia, USA, and China for use on non-food crops or ornamentals ${ }^{42,}$. Although 335 contamination of German groundwaters by daminozide was considered unlikely ${ }^{27}$, the 336 continued use of daminozide means its transport into surface waters remains a possibility, 337 especially in areas of heavy use. Additional information about the occurrence of daminozide 338 in surface waters and, more broadly, the potential for NDMA formation from chlorine 339 dioxide treatment of surface waters containing daminozide and/or other precursors with 340 hydrazine moieties is needed.

341 Since hydrazine and its derivatives are used in agriculture, as pesticides and fungicides, 342 in boiler feed water treatment and pharmaceutical production ${ }^{44}$, precursors with hydrazine 343 moieties are possible to be found in surface water or soil, like the pesticide maleic 344 hydrazide ${ }^{45}$. A study held in Iran with collected water samples from Karoon river detected a 345 hydrazine concentration of $0.4 \mu \mathrm{M}^{46}$. Because available occurrence data of daminozide in 346 water is limited, daminozide concentrations were analyzed in samples collected from a 347 Chinese wastewater treatment plant. The concentration of daminozide was $124.77 \pm 9.86 \mathrm{ng} / \mathrm{L}$ 348 in the influent and was $103.38 \pm 7.78 \mathrm{ng} / \mathrm{L}$ in the effluent. Furthermore, $\mathrm{ClO}_{2}$ oxidation $(2 \mathrm{mM})$ 349 was applied on filtered influent and the 5-day NDMA-FP was 71.18 $\pm 5.07 \mathrm{ng} / \mathrm{L}$ (Table S3). 350 Based on the NDMA yield from daminozide of 5.01\% (Table 1), daminozide was estimated 351 to account for $\sim 15 \%$ of the NDMA-FP from $\mathrm{ClO}_{2}$ oxidation. More sampling is required to 352 fully evaluate the importance of daminozide as an NDMA precursor across a diverse range of 353 surface water types and oxidation scenarios. This study also demonstrated that NDMA 
354 formation from oxidation of daminozide with $\mathrm{ClO}_{2}$ is distinct from that typically occurring 355 during the chloramination of wastewater impacted waters. Oxidation of daminozide by $\mathrm{ClO}_{2}$ 356 is fast, with significant NDMA formation within $10 \mathrm{~min}$, and with highest yields at $\mathrm{pH}$ 6-7. In 357 contrast, NDMA formation from wastewater-impacted waters chloramination is slow, 358 continuing through distribution systems and with highest yields around $\mathrm{pH} 8^{47}$. Therefore, 359 disinfecting at lower $\mathrm{pH}$, as suggested previously as a strategy for NDMA mitigation, would 360 maximize NDMA formation resulting from oxidation of hydrazine-containing precursors by $361 \mathrm{ClO}_{2}$. daminozide by ozone suggest its deployment as a pre-oxidant would also be counterproductive for NDMA control in waters containing precursors with hydrazine

365 moieties $^{27}$. Daminozide represents a class of NDMA precursors that react differently to preoxidation than other identified precursors. Consequently, site-specific variations in the 367 effectiveness of pre-oxidation at water treatment plants, or in the use of chlorine dioxide to treat stormwater or wastewater, are anticipated. Alternative precursor control strategies, such as sorption by activated carbon or pre-oxidation with free chlorine, are predicted to be more effective in these situations.

\section{Acknowledgements}

We thank the National Basic Research Program of China (2015CB459000), Guangdong

373 Natural Science Funds for Distinguished Young Scholar (2015A030306017) and State Key

374 Laboratory of Pollution Control and Resource Reuse (PCRRF13004) for their financial 375 support of this study.

\section{Supporting information}


377 Details of analytical methods and additional figures are included. This material is 378 available free of charge via the Internet at http://pubs.acs.org.

\section{References}

381 1. USEPA; National Center for Environmental Assessment (NCEA); Integrated Risk 382 Information System (IRIS) N-Nitrosodimethylamine Quickview (CASRN 62-75-9). http://cfpub.epa.gov/ncea/iris/index.cfm?fuseaction=iris.showQuickView\&substance_nmbr= $384 \underline{0045}$ (November 20, 2013),

386 http://www.waterboards.ca.gov/drinking_water/certlic/drinkingwater/NDMA.shtml

387 (December 29, 2013),

388 3. United States Environmental Protection Agency Contaminant Candidate List 3 - CCL.

389 http://water.epa.gov/scitech/drinkingwater/dws/ccl/ccl3.cfm (December 1, 2013),

390 4. Chen, B.; Nam, S.-N.; Westerhoff, P. K.; Krasner, S. W.; Amy, G., Fate of effluent 391 organic matter and DBP precursors in an effluent-dominated river: A case study of 392 wastewater impact on downstream water quality. Water Res 2009, 43, (6), 1755-1765.

393 5. Choi, J.; Valentine, R. L., Formation of N-nitrosodimethylamine (NDMA) from 394 reaction of monochloramine: a new disinfection by-product. Water Res 2002, 36, (4), 817395824.

396 6. Schreiber, I. M.; Mitch, W. A., Nitrosamine formation pathway revisited: the 397 importance of chloramine speciation and dissolved oxygen. Environ Sci Technol 2006, 40, 398 (19), 6007-6014.

399 7. Le Roux, J.; Gallard, H.; Croué, J.-P., Chloramination of nitrogenous contaminants 400 (pharmaceuticals and pesticides): NDMA and halogenated DBPs formation. Water Res 2011, $401 \quad 45,(10), 3164-3174$. 
402 8. Mitch, W. A.; Sedlak, D. L., Characterization and fate of N-nitrosodimethylamine 403 precursors in municipal wastewater treatment plants. Environ Sci Technol 2004, 38, (5), $404 \quad 1445-1454$.

4059 9. Shen, R.; Andrews, S. A., Demonstration of 20 pharmaceuticals and personal care 406 products (PPCPs) as nitrosamine precursors during chloramine disinfection. Water Res 2011, $407 \quad 45,(2), 944-952$.

408 10. Hanigan, D.; Thurman, E. M.; Ferrer, I.; Zhao, Y.; Andrews, S.; Zhang, J.; Herckes, 409 P.; Westerhoff, P., Methadone Contributes to N-nitrosodimethylamine Formation in Surface 410 Waters and Wastewaters during Chloramination. Environmental Science \& Technology $411 \quad$ Letters 2015.

412 11. Roux, J. L.; Gallard, H.; Croué, J.-P.; Papot, S.; Deborde, M., NDMA Formation by 413 Chloramination of Ranitidine: Kinetics and Mechanism. Environ Sci Technol 2012, 46, (20), $414 \quad 11095-11103$.

415 12. Zhao, Y. Y.; Boyd, J. M.; Woodbeck, M.; Andrews, R. C.; Qin, F.; Hrudey, S. E.; Li, 416 X. F., Formation of N-nitrosamines from eleven disinfection treatments of seven different 417 surface waters. Environ Sci Technol 2008, 42, (13), 4857-4862.

418 13. Shah, A. D.; Krasner, S. W.; Lee, C. F. T.; von Gunten, U.; Mitch, W. A., Trade-offs 419 in disinfection byproduct formation associated with precursor preoxidation for control of N420 nitrosodimethylamine formation. Environ Sci Technol 2012, 46, (9), 4809-4818.

421 14. Zhang, A.; Li, Y.; Song, Y.; Lv, J.; Yang, J., Characterization of pharmaceuticals and 422 personal care products as N-nitrosodimethylamine precursors during disinfection processes 423 using free chlorine and chlorine dioxide. J Hazard Mater 2014, 276, 499-509.

424 15. Lee, C.; Schmidt, C.; Yoon, J.; von Gunten, U., Oxidation of N-nitrosodimethylamine 425 (NDMA) precursors with ozone and chlorine dioxide: kinetics and effect on NDMA 426 formation potential. Environ Sci Technol 2007, 41, (6), 2056-2063. 
427 16. Jonnalagadda, S. B.; Nadupalli, S., Chlorine Dioxide for Bleaching, Industrial 428 Applications and Water Treatment. Indian Chem Eng 2014, 56, (2), 123-136.

429 17. Dietrich, A.; Hoehn, R.; Dufresne, L.; Buffin, L.; Rashash, D.; Parker, B., Oxidation 430 of odorous and nonodorous algal metabolites by permanganate, chlorine, and chlorine 431 dioxide. Water Sci Technol 1995, 31, (11), 223-228.

432 18. Yang, X.; Guo, W.; Lee, W., Formation of disinfection byproducts upon chlorine 433 dioxide preoxidation followed by chlorination or chloramination of natural organic matter. 434 Chemosphere 2013, 91, (11), 1477-1485.

435 19. Selbes, M.; Kim, D.; Karanfil, T., The effect of pre-oxidation on NDMA formation 436 and the influence of $\mathrm{pH}$. Water Res 2014, 66, 169-179

437 20. Stackelberg, P. E.; Furlong, E. T.; Meyer, M. T.; Zaugg, S. D.; Henderson, A. K.; 438 Reissman, D. B., Persistence of pharmaceutical compounds and other organic wastewater 439 contaminants in a conventional drinking-water-treatment plant. Sci Total Environ 2004, 329, $440 \quad(1-3), 99-113$.

441 21. Wang, W.; Ren, S.; Zhang, H.; Yu, J.; An, W.; Hu, J.; Yang, M., Occurrence of nine 442 nitrosamines and secondary amines in source water and drinking water: Potential of 443 secondary amines as nitrosamine precursors. Water Res 2011, 45, (16), 4930-4938.

444 22. American Public Health Association; American Water Works Association; Water 445 Environment Association, 20th ed.; Washington, DC, 1998.

446 23. Ripollés, C.; Pitarch, E.; Sancho, J. V.; López, F. J.; Hernández, F., Determination of 447 eight nitrosamines in water at the $\mathrm{ng} / \mathrm{L}$ levels by liquid chromatography coupled to 448 atmospheric pressure chemical ionization tandem mass spectrometry. Anal Chim Acta 2011, $449702,(1), 62-71$. 
450 24. Krauss, M.; Hollender, J., Analysis of nitrosamines in wastewater: exploring the trace 451 level quantification capabilities of a hybrid linear ion trap/orbitrap mass spectrometer. Anal 452 Chem 2008, 80, (3), 834-842.

453 25. Rutschmann, M. A.; Buser, H. R., Determination of daminozide and 454 dimethylhydrazine residues in Swiss apple juice concentrates using gas chromatography455 mass spectrometry. J Agr Food Chem 1991, 39, (1), 176-181.

456 26. Padhye, L. P.; Kim, J.-H.; Huang, C.-H., Oxidation of dithiocarbamates to yield N457 nitrosamines by water disinfection oxidants. Water Res 2013, 47, (2), 725-736.

458 27. Schmidt, C. K.; Brauch, H.-J., N,N-Dimethylsulfamide as Precursor for N459 Nitrosodimethylamine (NDMA) Formation upon Ozonation and its Fate During Drinking 460 Water Treatment. Environ Sci Technol 2008, 42, (17), 6340-6346.

461 28. Saxton, W. L.; Steinbrecher, K.; Gunderson, E., Results of a survey for the presence 462 of daminozide and unsymmetrical dimethylhydrazine in food. J Agr Food Chem 1989, 37, 463 (2), 570-573.

464 29. Babcock, L.; Pentecost, T.; Koppenol, W., Electron affinity of chlorine dioxide. $J$ 465 Phys Chem 1989, 93, (25), 8126-8127.

466 30. Gagnon, G.; Rand, J.; O’leary, K.; Rygel, A.; Chauret, C.; Andrews, R., Disinfectant 467 efficacy of chlorite and chlorine dioxide in drinking water biofilms. Water Res 2005, 39, (9), $468 \quad 1809-1817$.

469 31. Shen, R.; Andrews, S. A., NDMA formation kinetics from three pharmaceuticals in 470 four water matrices. Water Res 2011, 45, (17), 5687-5694.

471 32. Schonherr, J.; Bukovac, M. J., Dissociation constants of succinic acid 2, 2472 dimethylhydrazide. J Agr Food Chem 1972, 20, (6), 1263-1265.

473 33. Guo, L.; Matysik, F.-M.; Gläser, P.; Engewald, W., Determination of hydrazine, 474 monomethylhydrazine, 1,1-dimethylhydrazine, and 1,2-dimethylhydrazine by nonaqueous 
475 capillary electrophoresis with amperometric detection. Electrophoresis 2005, 26, (17), 33414763348.

477 34. Selbes, M.; Kim, D.; Ates, N.; Karanfil, T., The roles of tertiary amine structure, 478 background organic matter and chloramine species on NDMA formation. Water Res 2013, $479 \quad 47,(2), 945-953$.

480 35. Kemper, J. M.; Walse, S. S.; Mitch, W. A., Quaternary amines as nitrosamine 481 precursors: a role for consumer products? Environ Sci Technol 2010, 44, (4), 1224-1231.

482 36. Schmidt, C. K.; Sacher, F., Strategies for minimizing formation of NDMA and other 483 nitrosamines during disinfection of drinking water. In Water Quality Technology Conference 484 and Exposition Proceedings, Denver, 2006.

485 37. Park, S.-H.; Wei, S.; Mizaikoff, B.; Taylor, A. E.; Favero, C.; Huang, C.-H., 486 Degradation of amine-based water treatment polymers during chloramination as N487 nitrosodimethylamine (NDMA) precursors. Environ Sci Technol 2009, 43, (5), 1360-1366.

488 38. Park, S. H.; Padhye, L. P.; Wang, P.; Cho, M.; Kim, J.-H.; Huang, C.-H., N489 nitrosodimethylamine (NDMA) formation potential of amine-based water treatment 490 polymers: Effects of in situ chloramination, breakpoint chlorination, and pre-oxidation. $J$ $491 \quad$ Hazard Mater 2015, 282, (0), 133-140.

492 39. Latimer, J. G., Drought, Paclobutrazol, Abscisic Acid, and Gibberellic Acid as 493 Alternatives to Daminozide in Tomato Transplant Production. J Am Soc Hortic Sci 1992, $494 \quad 117,(2), 243-247$.

495 40. Toth, B.; Wallcave, L.; Patil, K.; Schmeltz, I.; Hoffmann, D., Induction of tumors in 496 mice with the herbicide succinic acid 2, 2-dimethylhydrazide. Cancer Res 1977, 37, (10), $497 \quad 3497-3500$. 
498 41. Rosenberg, B. J.; Barbeau, E. M.; Moure-Eraso, R.; Levenstein, C., The work 499 environment impact assessment: a methodologic framework for evaluating health-based 500 interventions. Am J Ind Med 2001, 39, (2), 218-226.

501 42. Hashemabadi, D.; Lipaei, S. R.; Shadparvar, V.; Zarchini, M.; Kaviani, B., The effect 502 of cycocel and daminozide on some growth and flowering characteristics of Calendula 503 officinalis L., an ornamental and medicinal plant. J Med Plants Res 2012, 6, (9), 1752-1757.

504 43. Buzzello, G. L.; Trezzi, M. M.; Marchese, J. A.; Xavier, E.; Miotto Junior, E.; Patel, 505 F.; Debastiani, F., Action of auxin inhibitors on growth and grain yield of soybean. Revista 506 Ceres 2013, 60, (5), 621-628.

507 44. Patil, K.; Rattan, T. M., Inorganic Hydrazine Derivatives: Synthesis, Properties and 508 Applications. John Wiley \& Sons: 2014.

509 45. Pajares, A.; Bregliani, M.; Massad, W.; Natera, J.; Challier, C.; Boiero, L.; 510 Montenegro, M.; García, N. A., On the natural fate of maleic hydrazide. Kinetic aspects of 511 the photochemical and microbiological degradation of the herbicide. $J$ Photoch Photobio B 512 2014, 135, (2014), 48-54.

513 46. Zargar, B.; Hatamie, A., A simple and fast colorimetric method for detection of 514 hydrazine in water samples based on formation of gold nanoparticles as a colorimetric probe. 515 Sensor Actuat B-chem 2013, 182, 706-710.

516 47. Krasner, S. W.; Mitch, W. A.; McCurry, D. L.; Hanigan, D.; Westerhoff, P., 517 Formation, precursors, control, and occurrence of nitrosamines in drinking water: A review. $518 \quad$ Water Res 2013, 47, (13), 4433-4450.

519 48. Le Roux, J.; Gallard, H.; Croué, J.-P., Formation of NDMA and halogenated DBPs by 520 chloramination of tertiary amines: the influence of bromide ion. Environ Sci Technol 2012, $52146,(3), 1581-1589$. 
522 49. Oya, M.; Kosaka, K.; Asami, M.; Kunikane, S., Formation of N523 nitrosodimethylamine (NDMA) by ozonation of dyes and related compounds. Chemosphere 524 2008, 73, (11), 1724-1730.

525 50. Mitch, W. A.; Sedlak, D. L., Formation of N-nitrosodimethylamine (NDMA) from 526 dimethylamine during chlorination. Environ Sci Technol 2002, 36, (4), 588-595.

527

528

529

530

531

532

533

534

535

536

537

538

539

540

541

542

543

544

545

546 
547 Table 1. Molar yields of NDMA from model precursors in this study and literature.

$$
\text { This study }
$$

\begin{tabular}{|c|c|c|c|c|c|}
\hline \multirow[t]{2}{*}{ Precursor } & $\mathrm{ClO}_{2}$ & $\mathrm{NH}_{2} \mathrm{Cl}$ & $\mathrm{ClO}_{2}-\mathrm{NH}_{2} \mathrm{Cl}$ & Previous studies & \multirow[t]{2}{*}{ Reference } \\
\hline & \multicolumn{4}{|c|}{ NDMA yield $(\% \mathrm{~mol} / \mathrm{mol})$} & \\
\hline \multirow{3}{*}{ DMA } & \multirow{3}{*}{ ND } & \multirow{3}{*}{$0.71( \pm 0.08)$} & \multirow{3}{*}{$0.87( \pm 0.06)$} & $0.24^{\mathrm{a}}$ & 5 \\
\hline & & & & $1.2^{\mathrm{a}}$ & 48 \\
\hline & & & & $3.0^{\mathrm{a}}$ & 15 \\
\hline \multirow[b]{2}{*}{ TMA } & \multirow[b]{2}{*}{$0.11( \pm 0.01)$} & \multirow[b]{2}{*}{$0.59( \pm 0.01)$} & \multirow[b]{2}{*}{$0.21( \pm 0.03)$} & $1.2^{\mathrm{a}}$ & \multirow[b]{2}{*}{34} \\
\hline & & & & $19^{\mathrm{a}}$ & \\
\hline DMBzA & $0.10( \pm 0.02)$ & $83.47( \pm 0.34)$ & $27.45( \pm 0.47)$ & $83.8^{\mathrm{a}}$ & 34 \\
\hline DMDC & $0.48( \pm 0.01)$ & $2.15( \pm 0.03)$ & $0.60( \pm 0.04)$ & $2^{\mathrm{a}}$ & 15 \\
\hline DMPD & $0.13( \pm 0.01)$ & $0.34( \pm 0.02)$ & $0.67( \pm 0.02)$ & $0.04^{\mathrm{b}}$ & 49 \\
\hline DMS & ND & $1.08( \pm 0.10)$ & $0.40( \pm 0.05)$ & $52^{\mathrm{b}}$ & 49 \\
\hline DMAI & ND & $5.61( \pm 0.13)$ & $5.02( \pm 0.04)$ & $6^{\mathrm{a}}$ & 15 \\
\hline DMAP & ND & $11.96( \pm 0.21)$ & $0.71( \pm 0.01)$ & $4.2^{\mathrm{a}}$ & 15 \\
\hline $\mathrm{BAC}^{*}$ & ND & $0.27( \pm 0.01)$ & $0.20( \pm 0.01)$ & $0.26^{\mathrm{a}}$ & 35 \\
\hline \multirow{3}{*}{ Ranitidine } & \multirow{3}{*}{ ND } & \multirow{3}{*}{$65.66( \pm 1.72)$} & \multirow{3}{*}{$21.50( \pm 0.83)$} & $40.2^{\mathrm{a}}$ & 7 \\
\hline & & & & $62.9^{\mathrm{a}}$ & 36 \\
\hline & & & & $82.7^{\mathrm{a}}$ & 31 \\
\hline Tetracycline & $0.31( \pm 0.01)$ & $0.54( \pm 0.04)$ & $0.28( \pm 0.03)$ & $1.2^{\mathrm{a}}$ & 9 \\
\hline PolyDADMAC ${ }^{*}$ & ND & $0.10( \pm 0.01)$ & $0.04( \pm 0.01)$ & $0.19^{\mathrm{a}}$ & 35 \\
\hline \multirow{2}{*}{ Daminozide } & $5.01( \pm 0.96)$ & \multirow{2}{*}{ ND } & $5.04( \pm 0.21)$ & \multirow{2}{*}{$55^{\mathrm{b}}$} & \multirow{2}{*}{27} \\
\hline & $3.61( \pm 0.10)^{*}$ & & $3.50( \pm 0.01)^{*}$ & & \\
\hline UDMH & $3.38( \pm 0.03)^{*}$ & $0.47( \pm 0.04)^{*}$ & $2.44( \pm 0.05)^{*}$ & $0.51^{\mathrm{a}}$ & 50 \\
\hline \multicolumn{6}{|c|}{$\begin{array}{l}\text { The values show the average } \pm \text { standard deviation for each yield. } \mathrm{ND}=\text { not detectable, yields }<0.034 \% \text {. } \\
\mathrm{ClO}_{2}: 0.2 \mathrm{mM} \mathrm{ClO} \mathrm{C}_{2}+2 \mu \mathrm{M} \text { precursor; } \mathrm{ClO}_{2}-\mathrm{NH}_{2} \mathrm{Cl}: 20 \mu \mathrm{M} \mathrm{ClO} \mathrm{O}_{2}+2 \mu \mathrm{M} \text { precursor for } 15 \text { min followed } \\
\text { by 5-day reaction with } 0.2 \mathrm{mM} \mathrm{NH} \mathrm{NH}_{2} \mathrm{Cl} ; \mathrm{NH}_{2} \mathrm{Cl}: 0.2 \mathrm{mM} \mathrm{NH}_{2} \mathrm{Cl}+2 \mu \mathrm{M} \text { precursor. } \\
\text { a NDMA molar conversion upon chloramination } \\
{ }^{b} \mathrm{NDMA} \text { molar conversion upon ozonation } \\
{ }^{*} \text { data was collected with initial precursors level }(1 \mathrm{mM}) \text { reacting with } 2 \mathrm{mM} \mathrm{ClO}_{2} \text {. }\end{array}$} \\
\hline
\end{tabular}




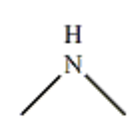

Dimethylamine (DMA)

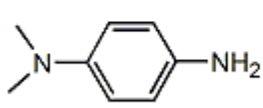

$\mathrm{N}, \mathrm{N}$-Dimethyl-p-phenylenediamine (DMPD)

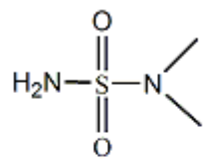

$\mathrm{N}, \mathrm{N}$-dimethylsulfamide (DMS)<smiles>CN/C(=C/[N+](=O)[O-])NCCSCc1ccc(CN(C)C)o1</smiles>

Ranitidine

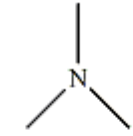

Trimethylamine (TMA)

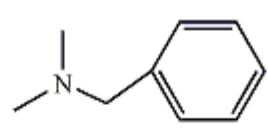

N,N-Dimethylbenzylamine (DMBzA)

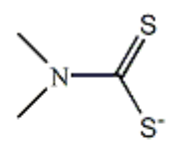

Dimethyldithiocarbanate (DMDC)

Figure 1.Structures of model compounds. 


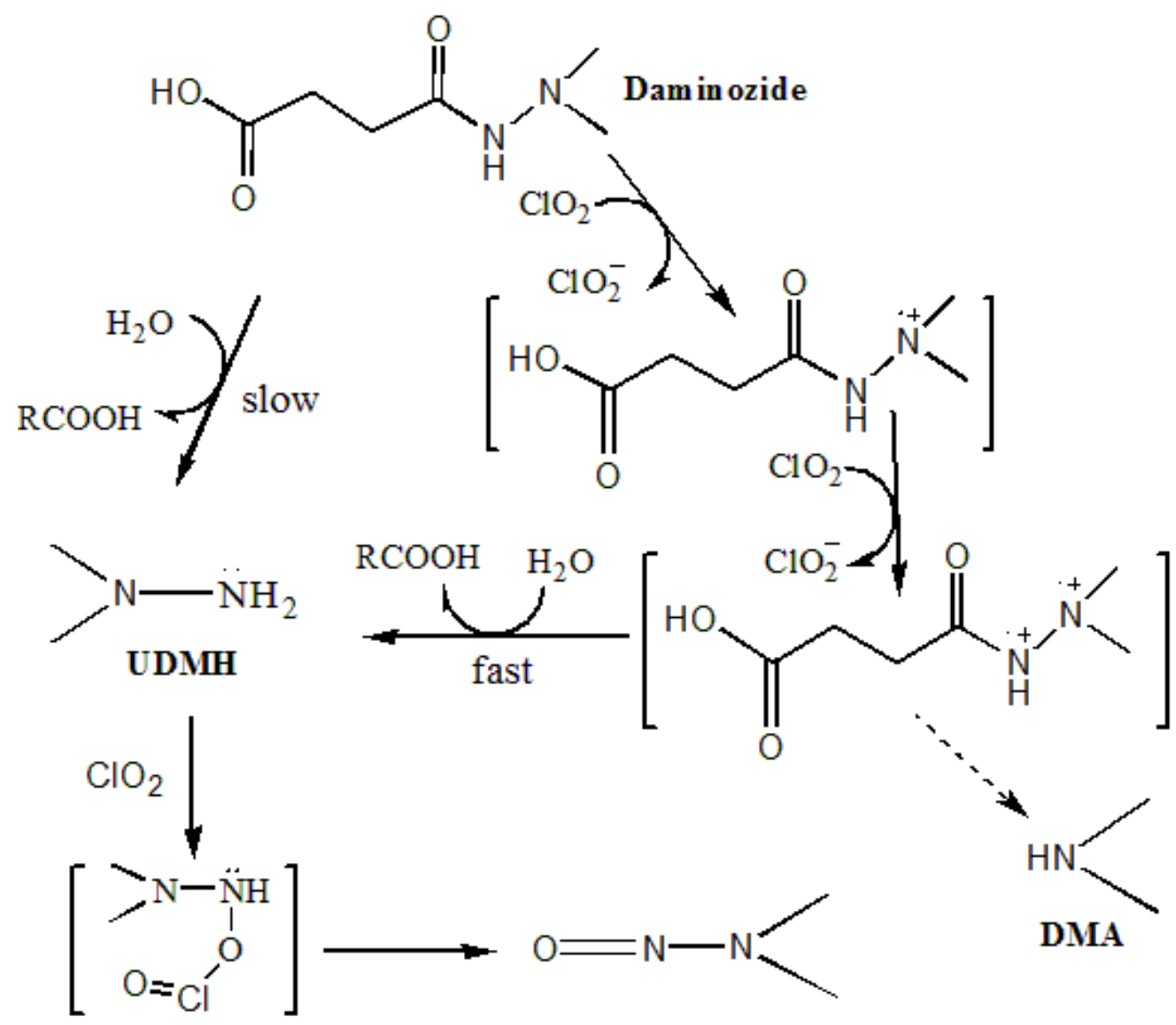

NDMA

Figure 2. Proposed NDMA formation mechanism from daminozide by $\mathrm{ClO}_{2}$. 


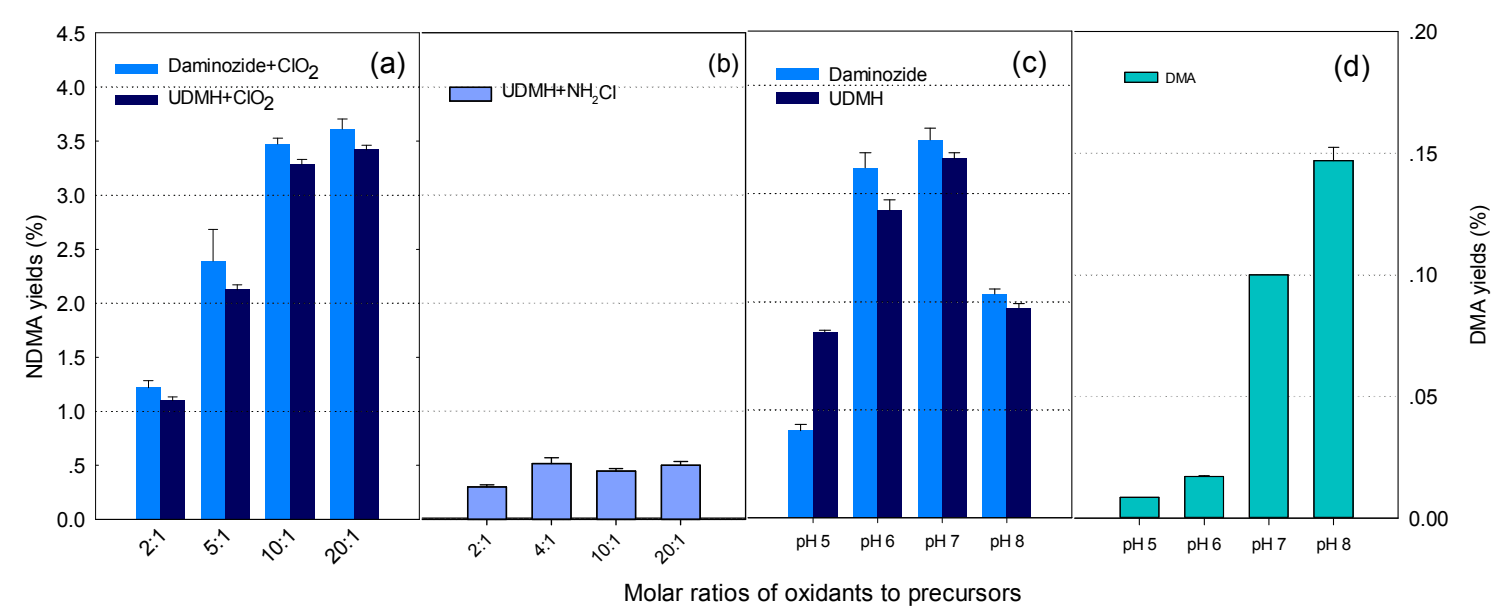

573
Figure 3. NDMA formation during oxidation of daminozide and $\mathrm{UDMH}$ by $\mathrm{ClO}_{2}$ and $\mathrm{NH}_{2} \mathrm{Cl}$ at $\mathrm{pH} 7$ and 5-day reaction with the variation of oxidant to precursor molar ratios (a-b) ([daminozide] or [UDMH] $=0.1 \mathrm{mM}, \mathrm{ClO}_{2}$ and $\mathrm{NH}_{2} \mathrm{Cl}$ varied from 0.2 to $2 \mathrm{mM}$.) and $\mathrm{pH}$ (cd) $\left([\right.$ daminozide $]$ or $\left.[\mathrm{UDMH}]=0.1 \mathrm{mM},\left[\mathrm{ClO}_{2}\right]=1 \mathrm{mM}\right)$. 


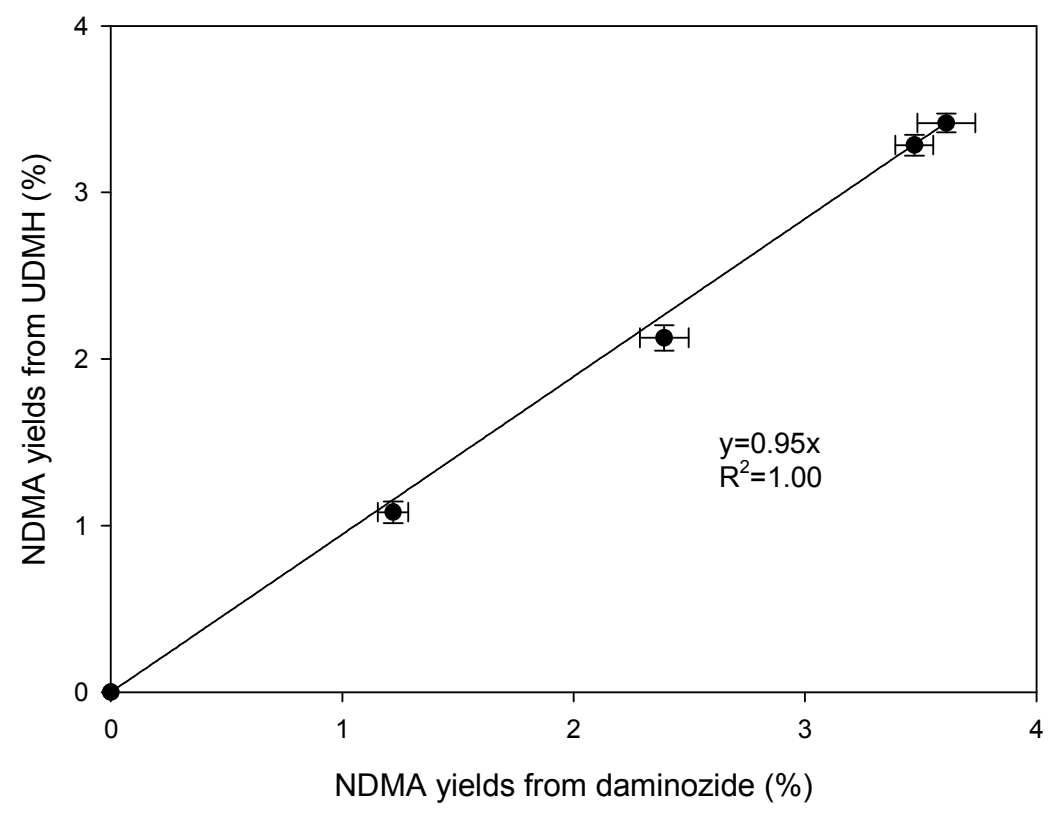

Figure 4. Linear relationship between NDMA formation from $\mathrm{ClO}_{2}$ oxidation of daminozide and UDMH: $100 \mu \mathrm{M}$ daminozide/UDMH, $0.2-2 \mathrm{mM} \mathrm{ClO}_{2}$ for 5 days. 


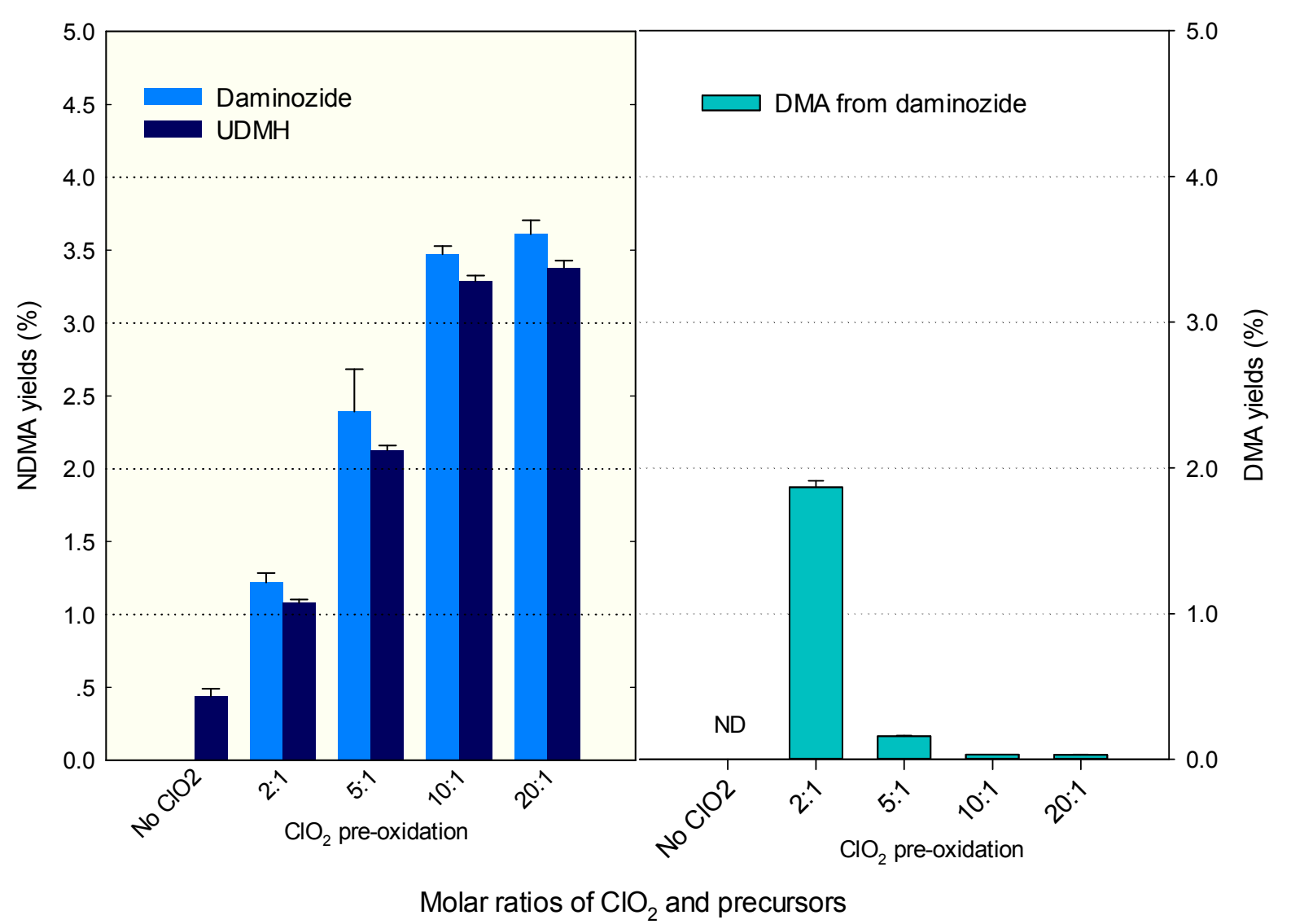

Figure 5. NDMA formation from $\mathrm{ClO}_{2}-\mathrm{NH}_{2} \mathrm{Cl}$ oxidation of daminozide and UDMH (left) 590 and DMA formation after $\mathrm{ClO}_{2}$ pretreatment of daminozide (right). Oxidation conditions $=$ $591 \quad 0.2-2 \mathrm{mM} \mathrm{ClO}_{2}$ followed by $2 \mathrm{mM} \mathrm{NH}_{2} \mathrm{Cl}$ for 5 days. 